\title{
Review of antimicrobial use and considerations in the elderly population
}

This article was published in the following Dove Press journal:

Clinical Interventions in Aging

\author{
Angela Giarratano' \\ Samantha EL Green' \\ David P Nicolau ${ }^{2}$ \\ 'Department of Pharmacy, Hartford \\ Hospital, Hartford, CT, USA; ${ }^{2}$ Center \\ for Anti-Infective Research and \\ Development, Hartford Hospital, \\ Hartford, CT, USA
}

\begin{abstract}
Pharmacologic management of infections in elderly patients presents multiple challenges to health care professionals due to variable pharmacokinetics, pharmacodynamics, and immune function. Age is a well-established risk factor for infection, but furthermore is a risk factor for prolonged length of hospital stay, increased incidence of complications, and significant and sustained decline in baseline functional status. In 2014, 46.2 million Americans were aged $\geq 65$ years, accounting for $14.5 \%$ of the total population. By 2033 , for the first time, the population of persons aged $\geq 65$ years is projected to outnumber the people $<18$ years of age. According to the National Ambulatory Medical Care Survey and the National Hospital Ambulatory Medical Care Survey, 154 million prescriptions for antimicrobials were estimated to have been written in doctors' offices and emergency departments during a 1-year time period. In 2014, 266.1 million courses of antimicrobials were dispensed to outpatients by US community pharmacies. A study that evaluated 2007-2009 Medicare Part D data found that patients aged $\geq 65$ years used more antimicrobials, at 1.10 per person per year, compared to 0.88 antimicrobials used per person per year in patients aged $0-64$ years. With the abundance of antimicrobial prescriptions and the current growth in the number and proportion of older adults in the US, it is essential that health care providers understand appropriate antimicrobial pharmacotherapy in the elderly patient. This review focuses on the use and implications of antimicrobial agents in the elderly population.
\end{abstract}

Keywords: infection, age, drug resistance, bacterial

\section{Introduction}

With an increasing elderly population in the US, and increasing antimicrobial resistance, it is important that health care providers understand how to utilize antimicrobials effectively and safely in this patient population. Americans aged $\geq 65$ years currently constitute $14.5 \%$ of the US population, but by 2030 it is estimated that this proportion will increase to $20 \% .^{1,2}$ Longer life spans and aging baby boomers will lead to a doubling of Americans aged $\geq 65$ years during the next 25 years, to approximately 72 million people, and two out of three of these older Americans have multiple chronic conditions. ${ }^{3}$ These chronic conditions predispose aging patients to increased risks for morbidity and mortality from infections compared to younger patients. The Centers for Disease Control and Prevention compared the leading causes of death, and numbers of death attributable to each respective cause, in patients aged $\geq 65$ years between 1980 and $2015 .{ }^{4}$ Consistently since 1980 , influenza and pneumonia have been in the top ten causes of death in this patient population, and in 2015, septicemia was the tenth leading cause of death in these patients. ${ }^{4}$ As patients age, the phenomenon of immunosenescence leads to increased risk of morbidity and
Correspondence: David P Nicolau Center for Anti-Infective Research and Development, Hartford Hospital, 80 Seymour Street, Hartford, CT 06102, USA

$\mathrm{Tel}+$ I $860972394 \mid$

Fax + I 8605453992

Email david.nicolau@hhchealth.org
Clinical Interventions in Aging 2018:13 657-667

657 
mortality secondary to infectious disease processes due to a decline in both quantitative and qualitative immune function. Effective and safe antimicrobial therapy is essential to keeping this vulnerable population healthy and preventing morbidity and mortality due to infection. To be able to provide effective antimicrobial therapy to this population, we must understand the altered pharmacokinetics and pharmacodynamics of drugs in elderly patients due to comorbid conditions and the normal physiological changes associated with aging. We also must understand the relevant and major drug-drug interactions commonly found in the elderly, consider differences in drug delivery, and appreciate the increased risk factors for multidrug-resistant infections in the elderly population. What follows is a review of the important considerations health care providers must understand before initiating antimicrobial pharmacotherapy in elderly patients.

\section{Considerations}

\section{Alterations in pharmacokinetics}

\section{Absorption}

There does not appear to be evidence for significant changes in antibacterial absorption via the digestive system in the elderly patient. ${ }^{5}$ However, as persons age, the gastrointestinal tract undergoes a variety of morphological and functional changes leading to delayed gastric emptying, reduced splanchnic blood flow, and alterations in $\mathrm{pH}^{6}$ Key pharmacokinetic parameters such as the bioavailability of orally administered medications are affected by these changes in the intraluminal environment (Table 1). ${ }^{7}$ Therefore, when treating elderly

Table I Changes in pharmacokinetic factors associated with aging and potential effects on antimicrobial dosing

\begin{tabular}{|c|c|c|c|c|c|}
\hline $\begin{array}{l}\text { PK } \\
\text { parameter }\end{array}$ & $\begin{array}{l}\text { Considerations in } \\
\text { elderly patients }\end{array}$ & $\begin{array}{l}\text { Impact on drug } \\
\text { pharmacokinetics }\end{array}$ & $\begin{array}{l}\text { Potential effects on } \\
\text { antimicrobial dosing }\end{array}$ & Example(s) & References \\
\hline \multirow[t]{2}{*}{ Absorption } & $\begin{array}{l}\text { Decreased gastric acid } \\
\text { production }\end{array}$ & Impaired drug dissolution & $\begin{array}{l}\text { Decreased bioavailability } \\
\text { of drugs }\end{array}$ & $\begin{array}{l}\text { Azithromycin, erythromycin, } \\
\text { cefaclor, ceftibuten, itraconazole, } \\
\text { ketoconazole, sulfonamides, } \\
\text { dapsone, pyrimethamine, atazanavir }\end{array}$ & $12,14,15$ \\
\hline & $\begin{array}{l}\text { Decreased gastric motility } \\
\text { Decreased small bowel } \\
\text { surface area } \\
\text { Decreased splanchnic blood } \\
\text { flow }\end{array}$ & $\begin{array}{l}\text { Decreased absorption of } \\
\text { drugs }\end{array}$ & $\begin{array}{l}\text { Standard dose may be } \\
\text { inadequate }\end{array}$ & Cefpodoxime proxetil & II \\
\hline \multirow[t]{5}{*}{ Distribution } & $\begin{array}{l}\text { Increased proportion of } \\
\text { adipose tissue }\end{array}$ & $\begin{array}{l}\text { Increased distribution of } \\
\text { lipid-soluble drugs }\end{array}$ & $\begin{array}{l}\text { Prolonged lipid-soluble } \\
\text { drug half-life }\end{array}$ & $\begin{array}{l}\text { Rifampin, fluoroquinolones, } \\
\text { macrolides, oxazolidinones, } \\
\text { tetracyclines, amphotericin B, } \\
\text { imidazole antifungals }\end{array}$ & 19,20 \\
\hline & $\begin{array}{l}\text { Decreased lean body mass } \\
\text { Decreased total body water }\end{array}$ & $\begin{array}{l}\text { Decreased distribution of } \\
\text { water-soluble drugs }\end{array}$ & $\begin{array}{l}\text { Increased plasma } \\
\text { concentration }\end{array}$ & $\begin{array}{l}\text { Aminoglycosides, glycopeptides, } \\
\text { beta-lactams }\end{array}$ & 19,20 \\
\hline & $\begin{array}{l}\text { Increased plasma alpha-I- } \\
\text { acid glycoprotein levels }\end{array}$ & $\begin{array}{l}\text { Decreased free } \\
\text { concentration of basic } \\
\text { antimicrobials }\end{array}$ & $\begin{array}{l}\text { Standard dose may be } \\
\text { inadequate }\end{array}$ & Macrolides & 21 \\
\hline & $\begin{array}{l}\text { Water accumulation near } \\
\text { infection site (edema, } \\
\text { ascites) }\end{array}$ & $\begin{array}{l}\text { Decreased concentration of } \\
\text { hydrophilic drugs in plasma } \\
\text { and at site of infection }\end{array}$ & $\begin{array}{l}\text { Standard dose may be } \\
\text { inadequate }\end{array}$ & & 22 \\
\hline & $\begin{array}{l}\text { Malnutrition/proteinuria } \\
\text { leading to hypoalbuminemia }\end{array}$ & $\begin{array}{l}\text { Increased concentration of } \\
\text { free drug }\end{array}$ & Drug toxicity & $\begin{array}{l}\text { Penicillins, ceftriaxone, } \\
\text { sulfonamides, clindamycin }\end{array}$ & $19,21,22,25$ \\
\hline \multirow[t]{2}{*}{ Metabolism } & $\begin{array}{l}\text { Liver disease; normal } \\
\text { physiological effects of aging } \\
\text { on the liver }\end{array}$ & $\begin{array}{l}\text { Decreased hepatic blood } \\
\text { flow } \\
\text { Decreased P450 CYP } \\
\text { enzyme activity }\end{array}$ & $\begin{array}{l}\text { Prolonged } \\
\text { drug half-life of } \\
\text { hepatically metabolized } \\
\text { drugs }\end{array}$ & $\begin{array}{l}\text { Macrolides, fluoroquinolones, azole } \\
\text { antifungals, antiretrovirals }\end{array}$ & $21,25,27$ \\
\hline & Polypharmacy & $\begin{array}{l}\text { Competition for CYP P450 } \\
\text { hepatic enzymes }\end{array}$ & Variable drug activity & $\begin{array}{l}\text { Macrolides, fluoroquinolones, azole } \\
\text { antifungals, antiretrovirals }\end{array}$ & $21,25,27$ \\
\hline \multirow[t]{2}{*}{ Elimination } & $\begin{array}{l}\text { Decreased renal function/ } \\
\text { renal disease }\end{array}$ & $\begin{array}{l}\text { Decreased renal blood flow } \\
\text { Decreased glomerular } \\
\text { filtration rate } \\
\text { Decreased drug removal }\end{array}$ & $\begin{array}{l}\text { Prolonged drug half-life } \\
\text { Accumulation of drug in } \\
\text { plasma } \\
\text { High serum } \\
\text { concentrations } \\
\text { Increased risk of toxicity }\end{array}$ & $\begin{array}{l}\text { Beta-lactams, glycopeptides, } \\
\text { aminoglycosides, daptomycin, } \\
\text { ciprofloxacin, levofloxacin, } \\
\text { trimethoprim/sulfamethoxazole }\end{array}$ & 31 \\
\hline & Renal replacement therapy & Increased drug removal & $\begin{array}{l}\text { Dose adjustment } \\
\text { required }\end{array}$ & & 32 \\
\hline
\end{tabular}

Abbreviation: PK, pharmacokinetic. 
patients with oral antimicrobials, it is important to consider the impact, even if small, that these gastrointestinal changes may have on drug absorption.

Many gastrointestinal tract disorders demonstrate higher incidence with advancing age. ${ }^{8}$ The mucosal layer of the gastrointestinal tract is an essential component to drug absorption and has been suggested to play a protective role within the gastrointestinal tract. Goblet cells are responsible for the production of mucus and as patients age, the number of goblet cells produced decreases. ${ }^{9}$ A suboptimal mucosal layer in an elderly patient may impact the rate and extent of drug absorption.

In elderly patients, the absorption of cefpodoxime proxetil is approximately $30 \%$ lower compared to younger patients. ${ }^{10}$ Additionally, the half-life of cefpodoxime proxetil has been shown to be $14 \%$ longer in elderly patients compared to younger patients, at 3 hours compared to 2.67 hours. ${ }^{11}$ However, neither of these differences in pharmacokinetics in elderly patients have been deemed clinically important, and therefore there are no recommendations for dosage adjustments in elderly patients for cefpodoxime proxetil.

Gastric $\mathrm{pH}$ can affect drug dissolution and absorption, as some formulations are best absorbed in either acidic or basic environments. There have been limited studies observing the changes in gastric $\mathrm{pH}$ in patients as they age. A study that compared the gastric acid secretion capacity of 29 young subjects and 79 elderly subjects concluded that gastric acid secretion does not appear to diminish with age. ${ }^{12}$ Gastric and duodenal $\mathrm{pH}$ in healthy elderly patients (mean age, $71 \pm 5$ years) under fasting conditions was 1.3 (range 1.1-1.6) and 6.5 (range 6.2-6.7), respectively. ${ }^{12}$ The $\mathrm{pH}$ of the stomach and duodenum under fasting conditions in 24 young subjects in this same study were 1.7 (range 1.4-2.0) and 6.1 (range 5.9-6.4), respectively. ${ }^{12}$ A study that measured the $\mathrm{pH}$ of the stomach in 14 young, healthy patients (mean age 30 years) found the fasting $\mathrm{pH}$ to be 2.05 (range 1.62-2.13). ${ }^{13}$ These studies suggest that the fasting $\mathrm{pH}$ of the gut does not change significantly as part of the normal aging process. However, when these studies looked at postprandial stomach and duodenal $\mathrm{pH}$, they found that in the elderly patients, it took longer to return to fasting $\mathrm{pH}$ after meals. ${ }^{12}$ The incidence of achlorhydria is about $10 \%-20 \%$ in elderly patients compared to $<1 \%$ in younger subjects. ${ }^{14}$ Elderly patients may also be on acid suppressive therapy, or calcium supplementation in the form of calcium carbonate, which would further increase their gastrointestinal $\mathrm{pH}$. Resultant increased gastric $\mathrm{pH}$ may affect antimicrobial bioavailability if the patient is taking the medication within 2-4 hours of a meal. Antimicrobials with reduced bioavailability when administered with food include azithromycin, erythromycin, cefaclor, and ceftibuten. ${ }^{15}$

Clinical data for drugs such as ketoconazole have shown reduced exposure (Cmax and AUC) in patients with a high gastric $\mathrm{pH}$. Antimicrobials with similar reduced absorption in high pH environments include itraconazole, ketoconazole, sulfonamides, dapsone, pyrimethamine, and atazanavir. For example, at $\mathrm{pH}$ of 2 , ketoconazole exhibits $100 \%$ dissolution after 30 minutes, versus only $10 \%$ dissolution after 60 minutes at $\mathrm{pH}$ greater than $6 .{ }^{16}$ This is extremely important, as acidlowering agents are used frequently in the outpatient and inpatient setting. A 2006-2010 National Ambulatory Medical Care Survey recorded that proton pump inhibitors were prescribed at 269.7 million adult ambulatory visits. ${ }^{17}$ With a significant number of patients on acid-suppressive therapies, loss of efficacy of drugs that require an acidic environment for dissolution and absorption is a valid concern. Weak acids in elevated $\mathrm{pH}$ environments can become more bioavailable, due to increased solubilization and dissolution. For example, raltegravir demonstrated a threefold increase in AUC and a fourfold increase in Cmax when administered concomitantly with omeprazole (Table 2 ). ${ }^{18}$ In order to avoid this potential alteration in intended drug bioavailability in elderly patients with elevated gastric $\mathrm{pH}$, coadministration with acidic beverages can be considered. Acidic carbonated beverages may temporarily lower the stomach $\mathrm{pH}$ in order to improve the dissolution and absorption of specific products. For example, the bioavailability of ketoconazole increases when administered with Coca-Cola ${ }^{\circledR}$ in patients who are also on a proton pump inhibitor. ${ }^{16}$

\section{Distribution}

Elderly patients tend to have an increased proportion of adipose tissue to lean mass compared to younger patients. With this increased fat content, lipophilic drugs will be more readily soluble in tissue compartments, leading to increased half-lives of lipid soluble drugs, including rifampin, fluoroquinolones, macrolides, oxazolidinones, tetracyclines, amphotericin B, and most of the imidazole antifungals. ${ }^{19,20}$ A concomitant decrease in total body water and lean mass contributes to decreased solubility of water-soluble drugs in tissue compartments, leading to increased plasma concentrations of hydrophilic drugs, including aminoglycosides, beta-lactams, and glycopeptides (Table 1). ${ }^{19,20}$ Due to this decreased total body water, elderly patients with severe infections should be administered full loading doses of 
Table 2 Effect of proton pump inhibitors on drug absorption ${ }^{71-75}$

\begin{tabular}{|c|c|c|c|c|}
\hline Drug & Omeprazole & Lansoprazole & Pantoprazole & Rabeprazole \\
\hline Clarithromycin & $\mathrm{a}$ & No effect & Unknown effect & Unknown effect \\
\hline Ketoconazole & $\downarrow$ Absorption & $\downarrow$ Absorption & Unknown effect & $\downarrow$ Absorption \\
\hline $\begin{array}{l}\text { Itraconazole } \\
\text { (capsules) }\end{array}$ & $\downarrow$ Absorption & $\downarrow$ Absorption & $\downarrow$ Absorption & $\downarrow$ Absorption \\
\hline Voriconazole $^{c}$ & $\begin{array}{l}\uparrow \text { Plasma drug } \\
\text { exposure (Cmax and AUC) }\end{array}$ & c & c & c \\
\hline $\begin{array}{l}\text { Posaconazole } \\
\text { (solution) }\end{array}$ & $\downarrow$ Absorption & $\downarrow$ Absorption & $\downarrow$ Absorption & $\downarrow$ Absorption \\
\hline Cefpodoxime $^{d}$ & $\downarrow$ Concentration & $\downarrow$ Concentration & $\downarrow$ Concentration & $\downarrow$ Concentration \\
\hline
\end{tabular}

Notes: $\downarrow$, decreased; $\uparrow$, increased. ${ }^{a}$ Omeprazole increases concentration of clarithromycin in the gastric mucous, while clarithromycin inhibits CYP 450 metabolism of omeprazole. 'traconazole capsules require an acidic environment for absorption. 'When initiating voriconazole in a patient receiving omeprazole at a dose of 40 mg/day or greater reduce the dose of omeprazole by $50 \%{ }^{74}$ (while in vivo studies were performed with omeprazole, other proton pump inhibitors can also inhibit metabolism of voriconazole via CYP 450 enzymes CYP 2C9 and/or CYP 3A4). 'There is no direct clinical evidence to confirm this interaction; however, the AUC of cefpodoxime has been shown to decrease by $40 \%$ when given with antacids such as aluminum/magnesium hydroxide and the histamine-2 receptor antagonist famotidine. ${ }^{75}$

Abbreviation: CYP 450, cytochrome P450.

aminoglycosides and glycopeptides when indicated. ${ }^{20}$ Additionally, increased plasma alpha-1-acid glycoprotein levels in elderly patients can lead to decreased free concentration of basic antimicrobials, including macrolides. ${ }^{21}$

Common chronic diseases and their complications, such as edema secondary to chronic heart failure, and ascites secondary to cirrhosis and chronic liver disease, also impact drug distribution in the elderly. These conditions can lead to fluid accumulation near the site of infection, causing dilution of standard doses of antimicrobials at the infection site, which can result in treatment failure even if plasma drug levels appear to be therapeutic. ${ }^{22}$ Additionally, decreased plasma albumin secondary to proteinuria, malnutrition, or chronic disease can lead to decreased protein-bound drug fraction, resulting in increased free concentration of drug in the plasma. ${ }^{19,22}$ This can result in increased free concentration of acidic antimicrobials, including penicillins, ceftriaxone, sulfonamides, and clindamycin. ${ }^{21}$

\section{Metabolism}

As discussed previously, studies have suggested that the mucosal layer undergoes significant changes in the elderly. Within the intestinal epithelium, there are numerous drug transporters, including p-glycoprotein (P-gp), and enzymes responsible for the absorption and bioavailability of drugs. ${ }^{23}$ Phase I and phase II metabolic processes occur in the intestinal wall, and many of the drug-metabolizing enzymes present in the liver are also present in the gut wall. ${ }^{24}$ In the elderly, changes to the intestinal epithelium may impact the bioavailability of antimicrobials that utilize these intestinal metabolic processes.

Reduced hepatic function as a result of normal aging or liver disease has a significant impact on the metabolism of hepatically metabolized antimicrobials in the elderly. Reduced hepatic blood flow or decreased hepatic function can lead to increased half-life of hepatically metabolized antimicrobials. ${ }^{25}$ Additionally, polypharmacy can lead to drug competition for cytochrome P450 (CYP 450) hepatic enzymes, resulting in increased half-lives of hepatically metabolized antimicrobials, including macrolides, fluoroquinolones, azole antifungals, and antiretrovirals (Table 1). ${ }^{21,26,27}$

\section{Elimination}

As patients age, there is an increased risk for decreased clearance of drug from the body due to declining function of the lung, kidney, bladder, gastrointestinal, and circulatory system, which leads to drug accumulation. ${ }^{28}$

Although estimated creatinine clearance calculated with the Cockcroft Gault equation takes into account patient age, age alone is not predictive of impaired renal function and therefore patient-specific factors must always be assessed when dosing antimicrobial agents. ${ }^{28}$ In the US, 4.9 million adults have kidney disease, and among those aged 60 years and older, the prevalence of chronic kidney disease is $39.4 \% .^{29,30}$ Renal function declines as part of the normal aging process, even without concomitant renal disease. Therefore, it is paramount to assess renal function when considering the pharmacokinetics of antimicrobial agents in elderly patients. The kidneys are essential for drug elimination of many antimicrobial agents, including but not limited to beta-lactams, glycopeptides, aminoglycosides, daptomycin, ciprofloxacin, levofloxacin, and trimethoprim/ sulfamethoxazole. With decreased renal function leading to impaired drug clearance, renally eliminated drugs can accumulate in the body resulting in prolonged half-lives, high serum concentrations, and increased risk of toxicity. ${ }^{31}$ 
When renal replacement therapy is utilized in advanced kidney failure, drugs may be eliminated to a greater extent than with normal renal elimination, requiring patient- and agent-specific dosage adjustments (Table 1). ${ }^{32}$

\section{Drug delivery}

\section{Oral administration}

There are many benefits of using oral administration compared with intravenous (IV) administration of antimicrobials in elderly patients, including reduced risk of infiltration, extravasation, fluid overload, catheter-related infections, and avoidance of pain associated with obtaining IV access.

Transitioning patients from IV to oral medications allows for earlier discharge from the hospital. ${ }^{33,34}$ However, dysphagia, which affects $15 \%$ of elderly Americans, can be a barrier to oral administration. ${ }^{35}$ In some patients, utilizing solution and suspension formulations instead of tablets and capsules may facilitate the administration process in patients with dysphagia, if they can be swallowed safely. However, characteristics of these liquid formulations including taste, texture, and volume required should be considered, as patients with dysphagia take substantially smaller sips than those without dysphagia. Additionally, since patients with dysphagia have decreased sensory awareness, too small of a volume to be swallowed could also present a challenge. ${ }^{36}$
Table 3 lists commonly used antimicrobials, their availability as a liquid formulation, and if they can or cannot be crushed. ${ }^{37-39}$

Feeding tubes are sometimes used to provide enteral nutrition and pharmacotherapy in patients with dysphagia. However, the absorption of antimicrobials administered via a feeding tube can be altered due to variations in stomach and duodenal $\mathrm{pH}$, site of delivery of medication, altered gastrointestinal motility time, adsorption of drug to the tubing, or use of a formulation incompatible with administration via a feeding tube. For example, if ciprofloxacin is administered through a feeding tube, crushed tablets should be used instead of a suspension due to an increased risk of tube blockage with the suspension formulation. ${ }^{40,41}$ In addition, the timing of enteral feeds can affect bioavailability of antimicrobial agents administered via a feeding tube. When enteral feeds are administered concomitantly with ciprofloxacin through a gastrostomy or jejunostomy tube, the bioavailability of ciprofloxacin is reduced by $27 \%-67 \%{ }^{42}$ Therefore, enteral feeds should be held for 1 hour before and 2 hours after fluoroquinolone administration. ${ }^{43}$ Additional examples of medications that should be separated from enteral tube feedings include doxycycline, metronidazole, penicillin $\mathrm{V}$, and voriconazole..$^{41}$ Additional information regarding recommendations for antimicrobial administration in patients with

Table 3 Common antimicrobials that are available as a liquid formulation and/or can be crushed ${ }^{37-39}$

\begin{tabular}{|c|c|c|c|}
\hline Drug & $\begin{array}{l}\text { Liquid formulation } \\
\text { available? }\end{array}$ & $\begin{array}{l}\text { Crushable/can } \\
\text { capsule be opened? }\end{array}$ & $\begin{array}{l}\text { Additional } \\
\text { information }\end{array}$ \\
\hline Penicillin $\mathrm{V}$ potassium & Yes & Yes & \\
\hline Amoxicillin & Yes & Yes (chewable tablet) & $\begin{array}{l}\text { Do not crush modified } \\
\text { release }\left(\text { Moxatag }^{\circledR}\right)\end{array}$ \\
\hline $\begin{array}{l}\text { Amoxicillin-clavulanate } \\
\text { potassium }\end{array}$ & Yes & Yes (chewable tablet) & $\begin{array}{l}\text { Do not crush modified } \\
\text { release (Augmentin } X R^{\circledR} \text { ) }\end{array}$ \\
\hline Cephalexin & Yes & Yes & \\
\hline Cefuroxime & Yes & $\begin{array}{l}\text { Not recommended due } \\
\text { to bad taste }\end{array}$ & \\
\hline Cefpodoxime & Yes & Yes & \\
\hline Azithromycin & Yes & Yes & \\
\hline Clindamycin & Yes & No & \\
\hline Nitrofurantoin & Yes & No & \\
\hline $\begin{array}{l}\text { Trimethoprim/ } \\
\text { sulfamethoxazole }\end{array}$ & Yes & Yes & \\
\hline Ciprofloxacin & Yes & $\begin{array}{l}\text { Not recommended due } \\
\text { to bad taste }\end{array}$ & $\begin{array}{l}\text { Do not crush modified } \\
\text { release }\left(\text { Cipro } X R^{\circledR}\right)\end{array}$ \\
\hline Levofloxacin & Yes & Yes & \\
\hline Moxifloxacin & No & Yes & \\
\hline Doxycycline & Yes & No & \\
\hline Metronidazole & No & $\begin{array}{l}\text { Suspension may be made } \\
\text { from crushing tablets }\end{array}$ & $\begin{array}{l}\text { Do not crush modified } \\
\text { release }\left(\text { Flagyl } E R^{\circledR}\right)\end{array}$ \\
\hline Rifampin & No & Yes & \\
\hline Linezolid & Yes & Yes & \\
\hline
\end{tabular}


limited gastrointestinal access can be found in the respective medication monograph or in the Handbook of Drug Administration via Enteral Feeding Tubes. ${ }^{41}$

\section{IV access}

Adequate IV access is important in order to quickly deliver life-saving antimicrobial medications to elderly patients being treated for microbial infections. The characteristics of the skin in elderly patients, including being thinner and more sensitive to bruising, can put elderly patients at increased risk of skin tears, hematomas, and other complications while trying to acquire and maintain adequate IV access. ${ }^{44}$ In a patient population with higher incidence of heart disease and greater stroke risk, these elderly patients are also more likely to be on antiplatelet and anticoagulant agents, increasing their risk of bleeding as a result of these IV access complications.

Endothelial function, or the ability of a vessel to synthesize and release nitric oxide and other vasodilatory and protective chemicals that inhibit vascular stenosis as a result of injury, has been shown to be reduced in elderly patients. ${ }^{45}$ This puts elderly patients at greater risk of suffering harm from administration of IV medications, and this should be considered when prescribing the route of antimicrobial administration. Although administration by mouth may result in reduced bioavailability due to altered absorption kinetics in the elderly, it may be favorable to IV administration in some cases.

Given the risks of infection and phlebitis with IV lines and the higher cost of IV antimicrobial formulations compared to oral formulations, it is important to advocate for the transition from IV to oral formulations as soon as clinically indicated. Although outpatient IV antimicrobial therapy may be required in the elderly population, identifying patients who may transition to oral therapy while in an inpatient setting can facilitate a faster discharge to home when continued IV access is not required. ${ }^{33,34}$ For example, patients who are consuming a regular diet, taking other oral medication formulations, and improving clinically may be candidates for transition from IV to oral therapy. Earlier discharge results in reduced length of stay and decreased risk of acquiring common health care-associated infections and multidrugresistant organism (MDRO) infections. ${ }^{46}$

\section{IM administration}

Intramuscular (IM) formulations of many antimicrobials are available and may be cost-efficient alternatives to IV therapies. IM formulations of cefazolin, gentamicin, penicillin, and imipenem are approximately one-tenth the cost of
IV therapy. ${ }^{47}$ In addition, IM therapy, which allows for selfadministration at home, could facilitate earlier hospital discharge in patients who may be resistant to being discharged to a nursing facility. However, many elderly patients may not be candidates for self-administration at home, and so clinical judgment in these cases must be used.

Pharmacokinetic studies of IM ceftriaxone demonstrated complete absorption in healthy adults and the pharmacokinetics in elderly subjects are minimally altered. ${ }^{48} \mathrm{IM}$ administration could be a consideration in patients who exhibit difficult IV access. ${ }^{49}$ However, it is important to note that IM administration of beta-lactam antimicrobials can be very painful and therefore should be reserved for patients without oral access who require short-term therapy or who exhibit difficulties in obtaining or maintaining IV access, as compliance may be compromised if a patient has to endure painful IM injections for extended periods of time. Lidocaine mixed with ceftriaxone for IM administration has been shown to mitigate the pain experienced with injection. ${ }^{49}$

Immunizations help protect the aging population from infections, including influenza and pneumonia. ${ }^{50}$ Appropriate administration of IM immunizations ensures an effective immune response and, subsequently, adequate active immunity. A 2006 study found that in elderly patients, body mass index (BMI) is correlated with deltoid subcutaneous layer thickness in both males and females. ${ }^{51}$ Additionally, females with the same BMI as males had significantly thicker subcutaneous layers $(p=0.0001)$ and thinner muscle layers $(p=0.0003) .{ }^{51}$ This study concluded that effective deltoid IM administration requires different needle lengths depending on patient BMI. ${ }^{51}$ In females with a BMI $<35 \mathrm{~kg} / \mathrm{m}^{2}$, and in males with any BMI, a minimum needle length of 25 $\mathrm{mm}$ for IM injection was recommended. ${ }^{51}$ In females with BMI greater than $35 \mathrm{~kg} / \mathrm{m}^{2}$, a minimum needle length of 32 $\mathrm{mm}$ is recommended. ${ }^{51}$ Ensuring appropriate needle length depending on patient BMI is especially important when administering immunizations to elderly patients, who are at increased risk of complications and death from vaccinepreventable illnesses. ${ }^{50}$

\section{Multidrug resistance Elderly patients and MDROs}

Antimicrobial drug resistance is one of the leading concerns in health care today. With few antimicrobial agents with novel mechanisms of action in the pipeline, the problem is likely to persist for the foreseeable future. Elderly patients are at increased risk of acquiring drug-resistant bacterial infections due to multiple factors including more frequent and prolonged 
contact with the health care system, chronic disease states that impair immune function, immunosenescence that comes with normal aging, and use of medical devices prone to bacterial colonization including indwelling catheters. Patients and residents in long-term care facilities are more likely to be colonized with at least one MDRO, including extendedspectrum beta-lactamase producers, methicillin-resistant Staphylococcus aureus (MRSA), and vancomycin-resistant Enterococcus (VRE). ${ }^{52}$ In 2012, 6.3 million elderly patients in the US used long-term care services, representing approximately $10 \%$ of the population of persons aged $\geq 65$ years. ${ }^{53,54}$ This represents a substantial portion of the elderly population potentially colonized with an MDRO, and therefore at risk for MDRO infection.

Compared to infections with antimicrobial-susceptible organisms, infection with an MDRO is associated with significantly increased mortality. ${ }^{55,56} \mathrm{~A}$ 12-year retrospective, single-center, surveillance study compared the rates of MRSA, VRE, and multidrug-resistant gram-negative (MDRGN) bacteria in cultures obtained within the first 48 hours of admission between patients aged $\geq 65$ years and patients $<65$ years old. ${ }^{57}$ There was a statistically significant higher admission prevalence in the older compared to the younger patients for each MDRO studied and for each year in the study. ${ }^{57}$ Additionally, the admission prevalence per 1,000 age-stratified admissions for MDROs increased in both the older and younger patients between 1998 and 2009, with VRE and MDRGN for both groups and MRSA for younger patients having statistically significant increases (Table 4).

A retrospective two-center study that evaluated 55427 bacterial isolates compared the proportion of antimicrobial-resistant strains in younger ( $<65$ years old) versus older ( $>65$ years old) hospitalized patients. ${ }^{58}$ Staphylococcus aureus isolates were more likely to be resistant to methicillin in older versus younger patients $(50.9 \%$ versus $40.9 \%$, respectively; $p<0.001$ ), while Enterococcus isolates were more likely to be resistant to vancomycin in younger patients versus older patients $(19.4 \%$ versus $16.5 \%$, respectively; $p=0.009) .{ }^{58}$ This data suggests that the frequency of resistance is not uniformly higher in bacteria isolated from elderly patients when compared to younger patients. Although elderly patients may be at increased risk of acquiring drugresistant bacterial infections compared to younger patients, current evidence suggests that the incidence of drug-resistant infections is not consistently higher in this population. This information has important implications for antimicrobial stewardship when treating elderly patients for bacterial infections. Increased risk factors for MDROs should not preclude a provider from deescalating antimicrobials when appropriate, as available evidence suggests that age alone does not predict incidence of MDRO infection.

\section{Drug interactions}

\section{Antimicrobials and warfarin: bleeding risk}

Warfarin is a commonly used anticoagulant for both prevention and treatment of thromboembolic events, as well as management of atrial fibrillation. Warfarin enacts its anticoagulant effect by inhibiting the vitamin K-dependent activation of clotting factors II, VII, IX, and X..$^{59}$ Antimicrobials can increase the anticoagulant effect of warfarin via CYP 450 2C9 inhibition and via reduction of the vitamin K-producing bacteria in the intestines. Medications, foods, and comorbidities can affect the intestinal bacterial synthesis of vitamin K. ${ }^{60}$ Poor oral intake and malnutrition can lead to increased warfarin efficacy due to lower vitamin $\mathrm{K}$ intake and stores, resulting in decreased production of clotting factors. ${ }^{60}$ Given that two-thirds of elderly persons in the US have multiple chronic conditions, this population is at a higher risk for malnutrition. ${ }^{3,60}$ A retrospective cohort study of 22272 US veterans who were prescribed warfarin for 30 days between 2002 and 2008 reviewed the risk of bleeding events within 30 days of antimicrobial exposure.$^{61}$ This study evaluated antimicrobials known to be high risk for significant drug interactions with warfarin: trimethoprim/ sulfamethoxazole, metronidazole, fluconazole, ciprofloxacin,

Table 4 Admission prevalence of MDROs 1998-2009

\begin{tabular}{|c|c|c|c|c|c|c|c|c|c|}
\hline \multirow[t]{4}{*}{ Age } & \multicolumn{9}{|c|}{ Admission prevalence (per I,000 age-stratified admissions) } \\
\hline & \multicolumn{3}{|c|}{ MRSA } & \multicolumn{3}{|l|}{ VRE } & \multicolumn{3}{|c|}{ MDRGN } \\
\hline & \multicolumn{2}{|l|}{ Year } & \multirow[t]{2}{*}{ p-value } & \multicolumn{2}{|l|}{ Year } & \multirow[t]{2}{*}{$p$-value } & \multicolumn{2}{|l|}{ Year } & \multirow[t]{2}{*}{$p$-value } \\
\hline & 1998 & 2009 & & 1998 & 2009 & & 1998 & 2009 & \\
\hline Elderly ( $\geq 65$ years) & 6.6 & 16.3 & 0.7 & 0.89 & 1.41 & $<0.01$ & 3.62 & 11.33 & $<0.01$ \\
\hline Young (<65 years) & 0.7 & 8.6 & $<0.01$ & 0.15 & 1.51 & $<0.01$ & 0.22 & 3.1 & $<0.01$ \\
\hline
\end{tabular}

Notes: MDRGN (Escherichia coli, Klebsiella spp., Enterobacter spp., Morganella spp., Proteus spp., Pseudomonas aeruginosa, Citrobacter spp., Acinetobacter spp.). Data from Denkinger et al. ${ }^{57}$

Abbreviations: MRSA, methicillin-resistant Staphylococcus aureus; VRE, vancomycin-resistant Enterococcus; MDRGN, multidrug-resistant gram-negative. 
levofloxacin, and clarithromycin. ${ }^{61}$ Results of this study showed that concomitant high-risk antimicrobials resulted in significantly increased bleeding risk (HR 1.48; 95\% CI 1.00-2.19). ${ }^{61}$ Early international normalized ratio (INR) evaluation occurring within 3-14 days of antimicrobial therapy initiation reduced the risk of serious bleeding events (HR 0.61; 95\% CI, 0.42-0.88). ${ }^{61}$ It is important for health care professionals to predict the increased risk of bleeding when prescribing high-risk antimicrobials to elderly patients on warfarin therapy, and to have procedures in place to ensure appropriate INR monitoring during concomitant antimicrobial and warfarin therapy.

Ideally, these high-risk antimicrobials should be avoided in patients on concomitant warfarin therapy in order to avoid potential increased risk of bleeding. However, when high-risk antimicrobials must be used, close INR monitoring should be implemented. For some agents, empirically decreasing the warfarin dose may be warranted. With concomitant trimethoprim/sulfamethoxazole or metronidazole therapy, consider reducing the warfarin dose by $25 \%-40 \%$; with fluconazole, consider reducing the warfarin dose by $25 \%{ }^{60}$

\section{Antimicrobials and direct-acting oral anticoagulants: bleeding risk}

When initiating antimicrobial therapy in a patient on concomitant direct-acting oral anticoagulant (DOAC) therapy, it is important to understand the potential drug-drug interactions in order to anticipate and prevent interactions that could lead to bleeding or clotting. Some antimicrobials affect P-gp transporter and CYP 450 3A4 enzyme function, resulting in drug interactions when administered concomitantly with DOACs. ${ }^{62}$ The bioavailability of dabigatran, a direct thrombin inhibitor, is significantly impaired by concomitant administration of rifampin, while with concomitant administration of itraconazole, exposure to dabigatran is significantly increased, leading to increased risk of bleeding. ${ }^{63}$ Clarithromycin, erythromycin, fluconazole, and ketoconazole can alter the metabolism of rivaroxaban, a direct factor $\mathrm{Xa}$ inhibitor $^{62,64}$ (Table 5).

Concomitant administration of CYP 450 enzyme inducers and/or P-gp transporter inducers with DOACs will result in increased metabolism of the DOAC, which can lead to subtherapeutic anticoagulant drug levels and resultant increased risk for stroke, heart attack, and thromboembolism. Rifampin is both a CYP 450 enzyme inducer and a P-gp transporter inducer, and therefore concomitant therapy with a DOAC can decrease the serum concentration of the DOAC, increasing the clotting risk. ${ }^{62,63,65}$ Antimicrobial CYP 450 enzyme inhibitors include clarithromycin, erythromycin, fluconazole, itraconazole, and ketoconazole, while P-gp transporter inhibitors include the macrolides, itraconazole, and ketoconazole. ${ }^{63}$ Concomitant administration of these CYP 450 and P-gp transporter inhibitors with DOACs will result in decreased metabolism of the DOAC, which can lead to increased anticoagulant drug exposure and resultant increased risk for fatal and non-fatal bleeding. ${ }^{65}$

\section{Interactions with laboratory tests}

It is important for clinicians to be mindful of potential interactions between antimicrobials and laboratory tests in order to appropriately anticipate and interpret the test results when caring for elderly patients.

Oritavancin, a glycopeptide used in acute bacterial skin and skin structure infections, has an important contraindication in concurrent use of IV unfractionated heparin for 120 hours, or 5 days, after oritavancin administration because it falsely elevates aPTT. ${ }^{66}$

The galactomannan antigen test, a diagnostic tool used to detect invasive Aspergillus infections, can produce false-positives in patients taking beta-lactam antimicrobials.

Table 5 Interactions between DOACs and antimicrobials ${ }^{62-64,76}$

\begin{tabular}{lllll}
\hline Drug & Dabigatran & Rivaroxaban & Apixaban & Edoxaban \\
\hline Mechanism & Direct thrombin & Direct factor Xa & Direct factor Xa & Direct factor \\
of action & inhibitor & inhibitor & inhibitor & Xa inhibitor \\
Metabolism & P-gP substrate & CYP 3A4 substrate & CYP 3A4 substrate & P-gp substrate $^{\text {b }}$ \\
Drug & Clarithromycin & Clarithromycin & Clarithromycin & Rifampin \\
interactions & Ketoconazole & Erythromycin & Itraconazole & \\
& Rifampin & Fluconazole & Ketoconazole & \\
& & Ketoconazole & Rifampin & \\
\hline
\end{tabular}

Notes: ${ }^{a}$ P-gP inhibitors include ketoconazole and should be avoided with dabigatran; rifampin is a P-gP inducer.63,76 ${ }^{b}$ Antimicrobial CYP 450 enzyme inducers include (but are not limited to) efavirenz, nevirapine, primidone, rifabutin, rifampin; antimicrobial CYP 450 enzyme inhibitors include (but are not limited to) erythromycin, azithromycin, ketoconazole, itraconazole.

Abbreviations: DOAC, direct-acting oral anticoagulant; P-gP, P-glycoprotein; CYP 450, cytochrome P450. 
Galactomannan is an antigen found in the cell wall of Aspergillus species, but the test has a low sensitivity and can cross-react with Penicillium species. ${ }^{67}$ Therefore, in patients taking beta-lactam antimicrobials derived from Penicillium species, false-positives can occur.

Significant and sustained increases in serum creatinine in patients with normal renal function have been reported in patients taking trimethoprim alone, or the combination trimethoprim and sulfamethoxazole. ${ }^{68}$ This elevation in serum creatinine lasted for up to 7 days after discontinuation of the drug. ${ }^{68}$

\section{Safety and tolerability QT interval prolongation}

Some antimicrobial agents can prolong the QT interval, leading to increased risk of Torsades de pointes (TdP). These agents include metronidazole, telavancin, macrolides, fluoroquinolones, hydroxychloroquine, chloroquine, quinine, itraconazole, ketoconazole, and fluconazole. ${ }^{69}$ Some of these agents increase the risk of TdP when taken alone, such as macrolides, fluoroquinolones, fluconazole, chloroquine, and hydroxychloroquine, while others put a patient at increased risk of TdP when taken concomitantly with other agents that can also increase the QT interval. ${ }^{69}$

\section{Adverse drug events}

An adverse drug event (ADE) surveillance project that estimated the frequency and rates of hospitalization after emergency department visits for ADEs from 2007 to 2009 concluded that $48.1 \%$ of the hospitalizations for ADEs involved adults aged 80 years and older. ${ }^{70}$ The annual national estimate of hospitalizations based on data from the National Estimates of Emergency Hospitalizations for Adverse Drug Events (NEISS-CADES) project reported that antimicrobial agents were involved in $3.8 \%$ of total hospitalizations for ADEs. ${ }^{70}$ Antimicrobial agents were the fifth most common therapeutic category involved in hospitalizations. ${ }^{70}$ The top ADEs associated with antimicrobial agents leading to hospitalization were allergic reactions $(36.2 \%)$, dyspnea and weakness $(22.5 \%)$, gastrointestinal effects $(20.5 \%)$, and neurologic effects $(18.3 \%) .{ }^{70}$ Neurological ADEs, dyspnea, weakness, and effects on blood pressure could have significant negative implications in elderly patients, leading to altered mental status, falls, and hypotension. Additionally, patient factors that increase the risk for hospitalization due to ADEs include alterations in pharmacokinetics and polypharmacy, both of which are pertinent to the elderly population. ${ }^{70}$
Elderly patients with decreased renal function as a result of normal aging or chronic kidney disease are especially at risk for complications and mortality when taking nephrotoxic antimicrobials, including aminoglycosides, vancomycin, beta-lactams, rifampin, and some of the fluoroquinolones. These patients are also more likely to experience polypharmacy, and may take nephrotoxic medications at baseline, such as nonsteroidal anti-inflammatory drugs, furosemide, and thiazide diuretics. When these medications are continued with incidental nephrotoxic antimicrobials, the combination can result in acute kidney injury and/or renal failure, which can lead to significant negative sequelae including requirements for temporary or permanent renal replacement therapy.

\section{Conclusion}

There are many considerations to be made when caring for elderly patients: multiple comorbidities, polypharmacy potentially resulting in drug interactions, pharmacokinetic and pharmacodynamic changes that can result in altered drug metabolism and subsequent toxic effects of drug accumulation, and an overall lack of drug study data in this patient population. With the number of Americans $\geq 65$ years expected to double in the next 25 years, it is essential that health care providers are aware of these challenges and have a comprehensive understanding of optimal, safe, and effective antimicrobial pharmacotherapy when caring for these elderly patients.

\section{Disclosure}

The authors report no conflicts of interest in this work.

\section{References}

1. Centers for Disease Control and Prevention. Get smart: know when antibiotics work in doctor's offices. Available from: https://www.cdc. gov/antibiotic-use/community/index.html. Published November 16, 2016. Updated March 22, 2017. Accessed February 16, 2018.

2. Castle SC, Uyemura K, Fulop T, Makinodan T. Host resistance and immune responses in advanced age. Clin Geriatr Med. 2007;23(3): 463-479, v.

3. Centers for Disease Control and Prevention. The state of aging and health in America 2013. Atlanta, GA: Centers for Disease Control and Prevention, US Department of Health and Human Services. 2013. Available from: https://www.cdc.gov/aging/pdf/State-Aging-Health-in-America2013.pdf. Accessed August 27, 2017.

4. National Center for Health Statistics. Health, United States, 2016: with Chartbook on Long-term Trends in Health. Hyattsville, MD: National Center for Health Statistics; 2017.

5. Noreddin AM, Haynes V. Use of pharmacodynamic principles to optimise dosage regimens for antibacterial agents in the elderly. Drugs Aging. 2007;24(4):275-292.

6. Wilkinson GR. The effects of diet, aging and disease-states on presystemic elimination and oral drug bioavailability in humans. Adv Drug Deliv Rev. 1997;27(2-3):129-159. 
7. Bai JPF, Burckart GJ, Mulberg AE. Literature review of gastrointestinal physiology in the elderly, in pediatric patients, and in patients with gastrointestinal diseases. J Pharm Sci. 2016;105(2):476-483.

8. Goldacre MJ. Demography of aging and the epidemiology of gastrointestinal disorders in the elderly. Best Pract Res Clin Gastroenterol. 2009;23(6):793-804.

9. Busse PJ, Mathur SK. Age-related changes in immune function: effect on airway inflammation. J Allergy Clin Immunol. 2010;126(4):690-699; quiz 700-701.

10. Borin MT, Ferry JJ, Forbes KK, Hughes GS. Pharmacokinetics of cefpodoxime proxetil in healthy young and elderly volunteers. J Clin Pharmacol. 1994;34(7):774-781.

11. Tremblay D, Dupront A, Ho C, Coussediere D, Lenfant B. Pharmacokinetics of cefpodoxime in young and elderly volunteers after single doses. J Antimicrob Chemother. 1990;26(Suppl E):21-28.

12. Feldman M. The mature stomach. Still pumping out acid? JAMA. 1997;278(8):681-682.

13. Ovesen L, Bendtsen F, Tage-Jensen U, Pedersen NT, Gram BR, Rune SJ. Intraluminal $\mathrm{pH}$ in the stomach, duodenum, and proximal jejunum in normal subjects and patients with exocrine pancreatic insufficiency. Gastroenterology. 1986;90(4):958-962.

14. Gidal BE. Drug absorption in the elderly: biopharmaceutical considerations for the antiepileptic drugs. Epilepsy Res. 2006;68 (Suppl 1): S65-S69.

15. Levison ME, Levison JH. Pharmacokinetics and pharmacodynamics of antibacterial agents. Infect Dis Clin North Am. 2009;23(4):791-815, vii.

16. Mitra A, Kesisoglou F. Impaired drug absorption due to high stomach $\mathrm{pH}$ : a review of strategies for mitigation of such effect to enable pharmaceutical product development. Mol Pharm. 2013;10(11):3970-3979.

17. Gawron AJ, Feinglass J, Pandolfino JE, Tan BK, Bove MJ, ShintaniSmith S. Brand name and generic proton pump inhibitor prescriptions in the United States: insights from the national ambulatory medical care survey (2006-2010). Gastroenterol Res Pract. 2015;2015:689531.

18. Iwamoto M, Wenning LA, Nguyen BY, et al. Effects of omeprazole on plasma levels of raltegravir. Clin Infect Dis. 2009;48(4):489-492.

19. Chutka DS, Evans JM, Fleming KC, Mikkelson KG. Drug prescribing for elderly patients. Mayo Clin Proc. 1995;70(7):685-693.

20. Jump RLP, Canaday DH. Infections in Older Adults, an Issue of Infectious Disease Clinics of North America. 1st ed. Atlanta, GA: Elsevier Science Health Science; 2017.

21. Faulkner CM, Cox HL, Williamson JC. Unique aspects of antimicrobial use in older adults. Clin Infect Dis. 2005;40(7):997-1004.

22. Pea F, Viale P, Furlanut M. Antimicrobial therapy in critically ill patients: a review of pathophysiological conditions responsible for altered disposition and pharmacokinetic variability. Clin Pharmacokinet. 2005;44(10):1009-1034.

23. Merchant HA, Liu F, Orlu Gul M, Basit AW. Age-mediated changes in the gastrointestinal tract. Int J Pharm. 2016;512(2):382-395.

24. Lin JH, Chiba M, Baillie TA. Is the role of the small intestine in first-pass metabolism overemphasized? Pharmacol Rev. 1999;51(2):135-158.

25. Schmucker DL. Liver function and phase I drug metabolism in the elderly: a paradox. Drugs Aging. 2001;18(11):837-851.

26. Gillum JG, Israel DS, Polk RE. Pharmacokinetic drug interactions with antimicrobial agents. Clin Pharmacokinet. 1993;25(6):450-482.

27. Stalam M, Kaye D. Antibiotic agents in the elderly. Infect Dis Clin North Am. 2004;18:533-549, viii.

28. Noreddin AM, El-Khatib W, Haynes V. Optimal dosing design for antibiotic therapy in the elderly: a pharmacokinetic and pharmacodynamic perspective. Recent Pat Antiinfect Drug Discov. 2008;3(1):45-52.

29. Centers for Disease Control and Prevention. Fast facts: kidney disease. Available from: https://www.cdc.gov/nchs/fastats/kidney-disease.htm. Published February 18, 2013. Updated March 30, 2017. Accessed August 28, 2017.

30. Mallappallil M, Friedman EA, Delano BG, McFarlane SI, Salifu MO. Chronic kidney disease in the elderly: evaluation and management. Clin Pract (Lond). 2014;11(5):525-535.
31. Wyatt CM, Kim MC, Winston JA. Therapy insight: how changes in renal function with increasing age affect cardiovascular drug prescribing. Nat Clin Pract Cardiovasc Med. 2006;3(2):102-109.

32. Trotman RL, Williamson JC, Shoemaker DM, Salzer WL. Antibiotic dosing in critically ill adult patients receiving continuous renal replacement therapy. Clin Infect Dis. 2005;41(8):1159-1166.

33. Carratalà J, Garcia-Vidal C, Ortega L, et al. Effect of a 3-step critical pathway to reduce duration of intravenous antibiotic therapy and length of stay in community-acquired pneumonia: a randomized controlled trial. Arch Intern Med. 2012;172(12):922-928.

34. Desai M, Franklin BD, Holmes AH, et al. A new approach to treatment of resistant gram-positive infections: potential impact of targeted IV to oral switch on length of stay. BMC Infect Dis. 2006;6:94.

35. Sura L, Madhavan A, Carnaby G, Crary MA. Dysphagia in the elderly: management and nutritional considerations. Clin Interv Aging. 2012;7:287-298.

36. Liu F, Ranmal S, Batchelor HK, et al. Patient-centered pharmaceutical design to improve acceptability of medicines: similarities and differences in paediatric and geriatric populations. Drugs. 2014;74(16):1871-1889.

37. Mitchell JF. Oral dosage forms that should not be crushed 2016. Institute for Safe Medication Practices. Available from: http://www.ismp.org/ tools/DoNotCrush.pdf. Updated 2016. Accessed December 2, 2017.

38. Pharmacist's Letter/Pharmacy Technician's Letter. PL technician tutorial, which tablets and capsules can be crushed, opened, or split? Available from: http://pharmacistsletter.therapeuticresearch.com/pl/ Browse. aspx ?cs $=$ HMG $\sim$ CEPDA \&s $=$ PL $\& p t=2 \& \mathrm{fpt}=31 \& \mathrm{dd}=310111 \&$ $\mathrm{pb}=\mathrm{PL} \& \mathrm{cat}=3003 \&$ segment $=7976$. Published August, 2014. Accessed December 20, 2017

39. Lexi-Drugs. Lexicomp Online. The Netherlands: Wolters Kluwer Clinical Drug Information, Inc. 2017. Available from: http://online. lexi.com/lco/. Accessed December 20, 2017.

40. Beckwith MC, Feddema SS, Barton RG, Graves C. A guide to drug therapy in patients with enteral feeding tubes: dosage form selection and administration methods. Hosp Pharm. 2004;39(3):225-237.

41. White R, Bardnam V. Handbook of Drug Administration via Enteral Feeding Tubes. 2nd ed. London: Pharmaceutical Press; 2011.

42. Healy DP, Brodbeck MC, Clendening CE. Ciprofloxacin absorption is impaired in patients given enteral feedings orally and via gastrostomy and jejunostomy tubes. Antimicrob Agents Chemother. 1996;40(1):6-10.

43. Williams NT. Medication administration through enteral feeding tubes. Am J Health Syst Pharm. 2008;65(24):2347-2357.

44. Moist LM, Lok CE, Vachharajani TJ, et al. Optimal hemodialysis vascular access in the elderly patient. Semin Dial. 2012;25(6):640-648.

45. Skaug EA, Aspenes ST, Oldervoll L, et al. Age and gender differences of endothelial function in 4739 healthy adults: the HUNT3 Fitness Study. Eur J Prev Cardiol. 2013;20(4):531-540.

46. Wong JG, Chen MI, Win MK, Ng PY, Chow A. Length of stay an important mediator of hospital-acquired methicillin-resistant Staphylococcus aureus. Epidemiol Infect. 2016;144(6):1248-1256.

47. Milkovich G, Piazza CJ. Considerations in comparing intravenous and intramuscular antibiotics. Chemotherapy. 1991;37 Suppl 2:1-13.

48. $\operatorname{Rocephin}^{\circledR}$ (ceftriaxone sodium) [package insert]. Lake Forest, IL: Hospira, Inc; 2017.

49. Russo TA, Cook S, Gorbach SL. Intramuscular ceftriaxone in home parenteral therapy. Antimicrob Agents Chemother. 1988;32(9): 1439-1440.

50. Centers for Disease Control and Prevention. Health, United States, 2016individual charts and tables: spreadsheet, PDF, and powerpoint files; Table 20. Available from: https://www.cdc.gov/nchs/hus/contents2016. htm\#020. Updated July 18, 2017. Accessed August 29, 2017.

51. Cook IF, Williamson M, Pond D. Definition of needle length required for intramuscular deltoid injection in elderly adults: an ultrasonographic study. Vaccine. 2006;24(7):937-940.

52. March A, Aschbacher R, Dhanji H, et al. Colonization of residents and staff of a long-term-care facility and adjacent acute-care hospital geriatric unit by multiresistant bacteria. Clin Microbiol Infect. 2010;16(7):934-944. 
53. Centers for Disease Control and Prevention. Long-term care services in the United States: 2013 overview. Available from: http://www.cdc.gov/ nchs/data/nsltcp/long_term_care_services_2013.pdf. 2013. Accessed November 28, 2017.

54. United States Census Bureau. Facts for features: older Americans month: May 2017. Available from: https://www.census.gov/newsroom/ facts-for-features/2017/cb17-ff08.html. Published April 10, 2017 Updated April 17, 2017. Accessed November 28, 2017.

55. Melzer M, Petersen I. Mortality following bacteraemic infection caused by extended spectrum beta-lactamase (ESBL) producing E. coli compared to non-ESBL producing E. coli. J Infect. 2007;55(3): 254-259.

56. Schwaber MJ, Carmeli Y. Mortality and delay in effective therapy associated with extended-spectrum beta-lactamase production in Enterobacteriaceae bacteraemia: a systematic review and meta-analysis. J Antimicrob Chemother. 2007;60(5):913-920.

57. Denkinger CM, Grant AD, Denkinger M, Gautam S, D’Agata EM. Increased multi-drug resistance among the elderly on admission to the hospital - a 12-year surveillance study. Arch Gerontol Geriatr. 2013 56(1):227-230.

58. Weber SG, Miller RR, Perencevich EN, et al. Prevalence of antimicrobialresistant bacteria isolated from older versus younger hospitalized adults: results of a two-centre study. J Antimicrob Chemother. 2009;64(6) 1291-1298.

59. Coumadin ${ }^{\circledR}$ (warfarin sodium) [package insert]. Princeton, NJ: BristolMyers Squibb; 2015.

60. Jacobs LG. Warfarin pharmacology, clinical management, and evaluation of hemorrhagic risk for the elderly. Clin Geriatr Med. 2006;22(1) 17-32, vii-viii.

61. Lane M, Zeringue A, McDonald JR. Serious bleeding events due to warfarin and antibiotic co-prescription in a cohort of veterans. Am J Med. 2014;127(7):657.e2-663.e2.

62. Lippi G, Favaloro EJ, Mattiuzzi C. Combined administration of antibiotics and direct oral anticoagulants: a renewed indication for laboratory monitoring? Semin Thromb Hemost. 2014;40(7):756-765.

63. Pradaxa ${ }^{\circledR}$ (dabigatran etexilate) [package insert]. Ridgefield, CT: Boehringer Ingelheim Pharmaceuticals; 2015.
64. Alam T, Clyne CA, White CM. Pharmacologic and nonpharmacologic thromboprophylactic strategies in atrial fibrillation. J Comp Eff Res. 2012;1(3):225-239.

65. Chang SH, Chou IJ, Yeh YH, et al. Association between use of nonvitamin $\mathrm{K}$ oral anticoagulants with and without concurrent medications and risk of major bleeding in nonvalvular atrial fibrillation. JAMA. 2017; 318(13):1250-1259.

66. Lexicomp Online. Oritavancin and heparin. In: Interactions. The Netherlands: Wolters Kluwer Clinical Drug Information, Inc. 2017 Available from: https://online.lexi.com/lco/action/home/interact. Accessed September 1, 2017.

67. Otting KA, Stover KR, Cleary JD. Drug-laboratory interaction between beta-lactam antibiotics and the galactomannan antigen test used to detect mould infections. Braz J Infect Dis. 2014;18(5):544-547.

68. Roy MT, First MR, Myre SA, Cacini W. Effect of co-trimoxazole and sulfamethoxazole on serum creatinine in normal subjects. Ther Drug Monit. 1982;4(1):77-79.

69. CredibleMeds. Combined list of drugs that prolong QT and/or cause Torsades de pointes (TDP). Oro Valley, AZ: AZCERT, Inc. 2013-2017. Available from: https://crediblemeds.org/pdftemp/pdf/CombinedList. pdf. Accessed September 1, 2017.

70. Budnitz DS, Lovegrove MC, Shehab N, Richards CL. Emergency hospitalizations for adverse drug events in older Americans. $N$ Engl J Med. 2011;365(21):2002-2012.

71. Vanderhoff BT, Tahboub RM. Proton pump inhibitors: an update Am Fam Physician. 2002;66(2):273-280.

72. Welage LS, Berardi RR. Evaluation of omeprazole, lansoprazole, pantoprazole, and rabeprazole in the treatment of acid-related diseases J Am Pharm Assoc (Wash). 2000;40(1):52-62.

73. Reilly JP. Safety profile of the proton-pump inhibitors. Am J Health Syst Pharm. 1999;56(23 Suppl 4):S11-S17.

74. Vfend ${ }^{\circledR}$ (voriconazole) [package insert]. New York, NY: Pfizer, Inc; 2011.

75. $\operatorname{Vantin}^{\circledR}$ (cefpodoxime proxetil) [package insert]. New York, NY: Pfizer, Inc; 2013.

76. Rifadin ${ }^{\circledR}$ (rifampin) [package insert]. Bridgewater, NJ: Sanofi-Aventis U.S. LLC; 2017.
Clinical Interventions in Aging

\section{Publish your work in this journal}

Clinical Interventions in Aging is an international, peer-reviewed journal focusing on evidence-based reports on the value or lack thereof of treatments intended to prevent or delay the onset of maladaptive correlates of aging in human beings. This journal is indexed on PubMed Central, MedLine,

\section{Dovepress}

CAS, Scopus and the Elsevier Bibliographic databases. The manuscript management system is completely online and includes a very quick and fair peer-review system, which is all easy to use. Visit http://www.dovepress. com/testimonials.php to read real quotes from published authors. 